\title{
Psalm 96: Israël en de volken
}

W A M Beuken

\begin{abstract}
Psalm 96: Israel and the Nations

A text immanent reading of Psalm 96 reveals an unlimited salvation-universalism. Israel's experience that her God surpasses the gods of the nations in solicitude and power persuades her that she should make room for these nations by her side "in the presence of YHWH". Subsequently, this hospitality inspires Israel to prophetically proclaim YHWH's kingship to these same nations. This confession does not only hold a guarantee for Israel herself but also offers certainty to the inhabitants of the world in their concern for the continued existence of the cosmos. Thus, side by side with the nations, Israel begins to share with them her expectation of the coming of YHWH as a hopeful prospect. God's coming will not happen as a special favour for Israel but as a revelation of his faithfulness. In short, YHWH will appear to the nations as the one who desired to be and was Israel's God.
\end{abstract}

\section{Werkvertaling}

1. Zingt voor JHWH een nieuw gezang/ zingt voor JHWH, heel de aarde.

2. Zingt voor JHWH, zegent zijn naam/ boodschapt van dag tot dag zijn bevrijding.

3. Vertelt onder de natiën zijn heerlijkheid/ onder alle volken zijn wonderbare daden.

4. "Waarlijk, groot is JHWH en zeer te prijzen/ vreeswekkend is hij boven alle goden.

5. Waarlijk, alle goden der volken zijn nietsgoden/ maar JHWH - hij maakt de hemelen.

6. Luister en schittering zijn voor zijn aangezicht/ sterkte en pracht in zijn heiligdom.

7. Huldigt JHWH, geslachten der volken/ huldigt JHWH om (zijn) heerlijkheid en sterkte.

8. Huldigt JHWH om de heerlijkheid van zijn naam/ brengt een offer en komt naar zijn voorhoven.

9. Buigt u neder voor JHWH in (zijn) heilige schittering/ beeft voor zijn aangezicht, heel de aarde."

10. Zegt onder de natiën: "JHWH - hij heerst als koning/ Ja, de wereld zal vaststaan, zij zal niet wankelen/

Hij zal de volken oordelen in rechtmatigheid".

11. De hemelen verheugen zich en de aarde juiche/ de zee bruise en haar volheid.

12. Het veld verblijde zich en alles wat daarop is./

Eens zullen jubelen alle struiken van de wildernis 
13. voor het aangezicht van JIIWH: waarlijk, hij komt/ waarlijk, hij komt om de aarde te richten.

14. Hij zal de wereld richten in gerechtigheid/ en de volken in zijn betrouwbaarheid.

De structuur

De colometrie van Psalm 96 wordt gekenmerkt door strakke regelmaat. Op éen uitzondering (vs 10) na vormen alle versregels bicola. Daarin overheersen de patronen $4+4$ (vs $2,4,7,8,12,13)$ en $4+3$ (vs $1,5,9,10 \mathrm{a}-\mathrm{b}, 11$ ), tweemaal onderbroken door $3+3$ (vs 3,6$)$, terwijl de laatste regel, vers $14,3+2$ vertoont 1 . Vers 10 wekt als enig tricolon achterdocht. Omdat het derde lid ("Hij zal de volken oordelen in rechtmatigheid") in enige handschriften en de paralleltekst van I Kronieken 16:31 ontbreekt (vgl BHS) en bovendien een variant vormt van Psalm 9:9; 98:9, beschouwen sommige auteurs deze zin als een mogelijke toevoeging 2 . Volgt men deze suggestie, dan groeperen de versregels zich tot vier stanza's - twee van drie versregels (vs 1-3, 4-6) en twee van vier (vs 7-10, 11-14) - volgens het volgende patroon: $4+3 / 4+4 / 3+3 / / 4+4 / 4+3 / 3+3 / / / 4+4 / 4+4$ $/ 4+3 / 4+3 / / 4+3 / 4+4 / 4+4 / 3+2$.

Deze indeling valt goed samen met het patroon van de zinsoorten in de eerste cola der versregels. In vers 1-3 en vers 7-10 beginnen beide cola van elke versregel met een imperativus pluralis behalve telkens het laatste colon van de laatste versregel (vs $3 b, 10 \mathrm{~b}$ ). In vers $4-6$ bevatten de cola nominale zinnen (vs $5 \mathrm{~b}$ een samengesteld nominale zin). De regels van vers 11-14 vangen met yiqtol (imperfectum of iussivus) aan, uitgezonderd vers 13, dat een eigen stilistische vorm vertoont (chiasme van "waarlijk, hij komt" in middenpositie).

Het feit dat de colometrische opbouw en het patroon van zinsoorten samenvallen, verleent de psalm een hechte structuur.

De spreker(s) en toegesprokene(n)

Terwijl de structuur zich gemakkelijk laat vaststellen, moet de lezer zich moeite getroosten om de wisseling van de dramatis personae te ontdekken. Vers 1 biedt hem nog een houvast in de aanspreking "heel de aarde", maar in vers 3 ("Vertelt onder de natiën / onder alle volken") blikt de psalmist zich te richten tot Israël zonder dat men dit kan afleiden uit een aparte aanspreking. Blikt men van vers 3 terug naar vers 2 , dan heeft de stilzwijgende wijziging van aanspreking zich in vers 2 voltrokken, want "zijn heerlijkheid / zijn wonderbare daden" (vs 3) staat extern parallel aan "zijn naam / zijn bevrijding" (vs 2). Voor beide toegesprokenen van verse 1-3, expliciet "heel de aarde" en impliciet Israël, geldt de oproep "zingt", maar waarschijnlijk vormen zij wegens de verschillende wijze van aanspreking niet eén koor. Daarmee komt de oproep aan de aarde zelfstandig te staan. Wij houden er rekening mee dat hij een prolepsis vormt, misschien een opschrift, waarvan de volle betekenis later zal blijken. In ieder geval bewerkt het naamloze optreden van Israël dat "heel de aarde" de volle aandacht trekt.

Het is aannemelijk dat het verhaal (vs 3: "Vertelt") van Israël in verse 4-6 vermeld staat. De inhoud van deze verzen leidt tot die gevolgtrekking, maar ook de karakteristieke aanhef met kî: "Waarlijk, groot is JHWH" (vs 4). Het is het verhaal 
van zijn transcendentie en immanentie: hij overtreft als Schepper alle (schijn) machten (vs 4-5) en zijn majesteit is in zijn heiligdom te ervaren (vs 6). Naar de inhoud is dit Israëls eigen verhaal, maar het lijkt gesitueerd "onder de volken" (vs 3), ofschoon deze niet worden aangesproken (vs 5: "alle goden der volken"). Het verhaal is nauwelijks polemisch ten opzichte van de volken, meer constaterend. Wat vooral ontbreekt, is dat Israël zich zijn God toeëigent, er prat op gaat dat JHWH zijn macht ten gunste van zijn eigen volk heeft ontplooid. Het verhaal van "zijn bevrijding" en "zijn wonderbare daden" (vs 2,3) had ook anders kunnen uitpakken, maar woorden als "wij" en "ons" treffen we er niet aan. Deze lof van JHWH legt geen beslag op hem.

Pas in vers 7-9 spreekt Israël overeenkomstig de opdracht van vers 3 de volken toe. De aansprekingen "geslachten der volken" (vs 7) en "heel de aarde" (vs 9) omsluiten dit segment. Wij stellen wél vast dat deze uitvoering van de opdracht uit vers 3 volgens een eigen interpretatie geschiedt. Vers 3 veronderstelt dat Israël te midden van de volken zijn verhaal zal vertellen, met andere woorden daarheen zal uitgaan, maar in vers 7-9 nodigt Israël de volken uit naar het heiligdom van JHWH in zijn eigen midden te komen. Dat is misschien nog niet zo duidelijk aan het drievoudige "huldigt" (een gebrekkige vertaling van het hebreeuwse ${ }^{3}$ ), maar wel aan de imperatieven "brengt een offer" en "komt naar zijn voorhoven"(vs 8).

Hier dringt zich trouwens zonneklaar een overeenkomst op tussen de zes imperatieven van vers $1-3$ en de zeven van vers 7-9:

Zingt(driemaal)
zegent
boodschapt
vertelt

huldigt(driemaal)

brengt een offer

komt

buigt u neder

beeft

De eerste serie eindigt met drie handelingen van spreken, de tweede met vier van cultisch eerbetoon, culminerend in "beven" ( 7 S 1 (I), dat in een dergelijke context de menselijke reactie op het verschijnen van God weergeeft (Ex 15:4; Deut 2:25; Jes 26:17; Hab 3:10; Ps 29:8; 77:17;97:4)4. Kortom, Israël nodigt de volken uit de aanwezigheid van JHWH in zijn tempel te ervaren.

Het verrassende van dit segment is dat Israël de volken toegang geeft tot de plaats waar hij het verhaal van zijn eigen geschiedenis met JHWH viert, kennelijk met de bedoeling dat zijn eigen verhaal ook dat van de volken kan worden. Niet voor niets keren zoveel woorden uit de oproep aan Israël en zijn eigen verhaal in deze uitnodiging terug: "heerlijkheid" (vs 3 en 7,8), "sterkte" (vs 6 en vs 7), "zijn naam" (vs 2 en vs 8), "schittering" (vs 6 en vs 9), "heiligdom" en "heilig" (vs 6 en vs 9) en ten slotte "zijn aangezicht" (vs 6 en vs 9). Met name door de volken uit te nodigen om te verschijnen "voor het aangezicht van JHWH" - een verrassende climax ten opzichte van "zijn voorhoven" (vs 8) - ruimt Israël voor de volken een plaats in naast zichzelf in zijn verhouding tot zijn God.

Met vers 9 had de psalm kunnen eindigen. De wezenlijke onderdelen van het literaire genre lofliederen zijn verwerkelijkt: de aansporing tot lof (vs 2-3), het lied van Gods daden (vs 4-6) en de oproep aan derden om met de lof in te stemmen (vs 7-9). Maar de dynamiek van spreker en toegesprokene is nog niet ten einde. Opnieuw krijgt Israël de opdracht om onder de volken het woord te nemen en wordt 
hem de inhoud van een boodschap aangereikt (vs 10). Deze boodschap is van geheel andere aard dan Israëls eigen verhaal (vs 4-6). Zij behelst twee punten: het koningschap van JHWH en de veiligheid van de kosmische en sociale wereldorde, die vanouds de bekommernis der volken uitmaakt. Daarover later meer. Hier volstaat het op te merken dat deze boodschap zich tot vers 7-9 verhoudt als profetie tot (uitnodiging tot) cultus.

In vers 11 bereikt de dynamiek van spreker en toegesprokene een nieuw knooppunt. De aanspreking is niet langer rechstreeks. De iussivusvorm van de werkwoorden in vers $11-12$ a ("verheugen zich... juiche... bruise... verblijde") 5 maakt "de hemelen", "de aarde", "de zee" en "het veld" tot actanten, betrekt hen als deelnemers bij het communicatieve spel van de psalm. Deze vier omvatten volgens een bepaalde indeling van de kosmos het geheel van de schepping. Het zijn als het ware de verticale en horizontale dimensies van al het bestaande, terwijl "haar volheid" en "alles wat daarop is" de fauna en flora aangeven6. Aldus wordt wat in de boodschap van vers 10 nog onderwerp van gesprek is, "de wereld" (לבA), samen met de andere domeinen van de kosmos getuige van Israëls spreken tot de volken. Daarmee schept de kosmos een ambiance van verwelkoming voor het verschijnen van JHWH als koning en voor zijn weldaden jegens de wereld. Het geheel waartoe de besprokene (vs 10) behoort, wordt uitgenodigd om als spreker op te staan en de betrouwbaarheid van de voorafgaande boodschap in uitingen van vreugde te belijden (vs 11-12a).

Deze nieuwe actant draagt zelf een dynamiek in zich. Een vijfde domein van de kosmos, "alle struiken van de wildernis" (vs $12 b)^{7}$, voegt zich numeriek bij de vier voorgaande: "de hemelen", "de aarde", "de zee" en "het veld". Een gelijksoortige handeling, "jubelen", wordt eraan toegekendt, in vervolg op "zich verheugen", "juichen", "bruisen" en "zich verblijden". Maar de werkwoordsvorm verschilt wezenlijk: geen iussivus, maar een imperfectum ("zullen jubelen") ${ }^{8}$,vergezeld van de tijdsbepaling "eens" $\left(\boldsymbol{T}()^{9}\right.$. In goed grammaticale termen uitgedrukt: de aanvoegende wijs gaat over in de aantonende wijs. Daarmee worden "de struiken van de wildernis" juist geen actant binnen het gebeuren van de psalm. "De hemelen", "de aarde", "de zee" en "het veld" staan nog binnen de kring van wie in deze psalm optreden, mar "de struiken van de wildernis" staan daarbuiten, bevinden zich achter de horizon, niet in de overzienbare ruimte, zoals ook niet in de overzienbare tijd ("eens"). Daarmee wordt "de wildernis" weer object van spreken, zoals "de wereld" in vers 10 .

Op deze wijze bezorgt de afwisseling van spreker en toegesprokene de psalm een open einde. Israëls nieuwe boodschap aan de volken loopt erop uit dat het onderwerp van zijn boodschap, de kosmos, zich bij hem voegt in het spreken over God, niet als gesprekspartner tegenover hem, maar als klankbord. De kosmos mag in vreugde de boodschap hem aangaande bevestigen. Deze getuige, waarvan de stem is samengesteld uit alle bewoonde domeinen van de werkelijkheid, zal niet verstommen. Eens zal ook de stem van de woestenij, nu het domein van de onvruchtbaarheid, daarin opgaan. Aldus vormt Israëls boodschap een spanningsboog tussen het spreken dat zich nu in de psalm voltrekt, en het tijdstip waarop JHWH sal komen. De lof van God leidt tot de aanvaarding van de volken vór JHWH niet als het einde van de geschiedenis, maar in de verwachting van zijn komst, een gebeurtenis waarin de gehele schepping, zelfs de wildernis, zal zijn betrokken. 


\section{Het gesprokene}

Het verband tussen spreker en toegesprokene enerzijds en het gesprokene anderzijds is in beginsel onverbreekbaar. Men mag deze elementen slechts kortstondig losmaken, helemaal kan dat nooit. Daarom is in het voorafgaande ook reeds het nodige gezegd over het gesprokene. Maar hier vervolgen wij die lijn kat'exochén.

Nadat wij gezien hebben wat er in de psalm op communicatief niveau gebeurt, kan men beter begrijpen dat vers 1 als een anticiperend kopje fungeert. Nu valt ook op dat "een nieuw gezang" en "heel de aarde" daarin de twee enige variabelen zijn bij het herhaalde "zingt voor JHWH". Het feit dat en de wijze waarop de aarde in deze psalm ertoe komt te zingen voor JHWH, maakt dat lied tot iets nieuws. Zoals reeds vaker is opgemerkt, heeft "een nieuw gezang" in een dergelijke context niet de betekenis van een nieuwe tekst of een nieuwe melodie, maar van een nieuw gebeuren dat ertoe noopt JHWH te bezingen ${ }^{10}$.

De psalmist houdt Israël in zijn oproep God te bezingen vier traditionele theologoumena als kristallisatiepunten voor zijn lofprijzing voor: "de naam", "de bevrijding", "de heerlijkheid" en "de wonderbare daden van JHWH" (vs 2-3). Deze kenmerken niet én bepaalde historische ervaring van Israël, eerder bergen zij het feit dat Gods reddende nabijheid zich heeft herhaald en de mogelijkheid dat dit nog eens zal gebeuren. Toch structureert hun betekenis zich tot een patroon. "Naam" en "heerlijkheid" belichamen dat JHWH zich in Israëls geschiedenis openbaart, "bevrijding" en "wonderbare daden" beklemtoon dat God in Israëls bestaan een wending ten goede tot stand heeft gebracht. De laaste term verwijst bovendien naar het feit dat Gods handelen Israëls bevattingsvermogen te boven gaat ${ }^{11}$. Daarom past dit woord goed als laatste in de rij. Het drukt de potentialiteit van nieuwe ervaringen uit. In ieder geval geeft de oproep van vers 2.3 te kennen dat het verhaal van de eigen lotgevallen ondergeschikt moet zijn aan wat men daaruit over JHWH te weten komt.

Het valt op dat Israël in zijn lof (vs 4-6) de theologoumena van de oproep (vs 2-3) niet met dezelfde woorden herhaalt. Zij werken wel door omdat JHWH naar zijn transcendentie en immanentie wordt geschilderd. Zijn verhevenheid komt naar voren in het feit dat hij alle machten die op aarde verering vinden, overtreft (vs 4 5a), maar ook, of daarom, in het feit dat de hemelen zijn werk vormen (vs 5b). Zijn tegenwoordigheid op aarde concentreert zich "in zijn heiligdom", waar Israël "voor zijn aangezicht" zijn numinositeit ("luister en schittering") en zijn indrukwekkende kracht ("sterkte en pracht") viert (vs 6) ${ }^{12}$.

In zijn uitnodiging aan de volken om deel te nemen aan de eredienst van JHWH (vs 7-9) verbindt Israël theologoumena die de psalmist hem heeft voorgehouden, met andere die hij zelf in zijn lof van God naar voren heeft gebracht: enerzijds "heerlijkheid" en "naam" (vs 7-8 en vs 2-3), anderzijds "sterkte", "schittering" en "aangezicht" (vs 7-9 en vs 6). Door de opname van deze semantemen en de verdeling ervan komt sterk tot uitdrukking dat Israël enerzijds de uitnodiging tot Gods lof doorgeeft aan "de geslachten der volken" (vs 7), anderzijds zijn kennis van JHWH aan hen ter beschikking stelt. Dit alles dient de verering van JHWH door "heel de aarde" (vs 9).

De nieuwe profetische boodschap van Israël voor de volken brengt een heel 
ander thema aan: het koningschap van JHWH (vs 10). Toch is de zin "JHWH - hij

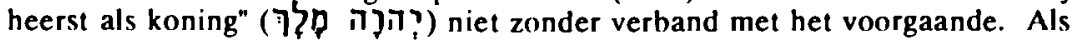
zinsoort heeft hij in het voorafgaande één evenbeeld: "JHWH - hij maakt de

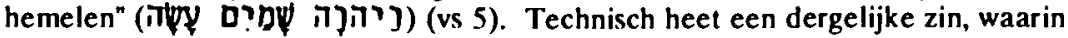
het werkwoord niet voorop staat, een samengesteld nominale zin. Hij beschrift een handeling niet als een onderdeel van een narratief vervolg, maar als kenmerk van het vooropgestelde zinsdeel, in dit geval JHWH. Door de exclusieve overeenkomst in zinsoort van vers 10 a met vers 5 b legt de psalm een verband tussen JHWH's koningschap en zijn scheppingsmacht, een verband dat natuurlijk een gegeven van Israëls overlevering is.

Het verband tussen deze twee attributen van JHWH in vers $5 b$ en vers $10 \mathrm{a}$ wordt versterkt door het feit dat "de hemelen" en "de wereld" complementaire begrippen vormen. Weliswaar geldt dit eerder het koppel hebreeuwse woorden

D? dat sterk het bewoonde vasteland als onderdeel van de aarde connoteer ${ }^{13}$, zal ingegeven zijn door het thema van de veiligheid van de aardschijf voor haar bewoners. De hemelen maken en ervoor zorgen dat de wereld niet wankelt, zijn complementaire activiteiten, vergelijkbaar met wat de latere overlevering als schepping en instandhouding heeft onderscheiden. Zoals de macht van JHWH, in Israëls geschiedenis betoond, tot de gevolgtrekking leidt dat hij de maker van de hemelen is (vs 5), zo leidt dit laatste attribuut, als koningschap van goddelijke orde geïterpreteerd, weer tot de gevolgtrekking dat de tegenpool van de hemelen, het woongebied van de mensen ofwel "de wereld" onder zijn bestier vaststaat (vs 10) ${ }^{14}$. Het derde colon van vers 10 ("Hij zal de volken oordelen in rechtmatigheid") keert terug naar JHWH als subject (vs 10a) en expliciteert de veiligheid van de wereld in termen van een billijke rechtspraak 15 in de samenleving van de volken.

In de merkwaardige overgang van de aanvoegende naar de aantonende wijs, van iussivi naar imperfectum met tijdsbepaling, in vers 11-12 komt de lijn van het gesprokene weer boven. Wat dit inhoudt voor vers $12 \mathrm{~b}$, is in de vorige paragraaf reeds aangegeven. Wat wij nog niet hebben uitgewerkt, is de verbinding van vers $12 \mathrm{~b}$ met vers 13-14 door middel van een enjambement. Kortom, het gaat om het volgende tekstsegment, dat wij als mededeling, onderscheiden van de voorafgaande aansporing, mogen beschouwen:

12b Eens zullen jubelen alle struiken van de wildernis.

13 voor het aangezicht van JHWH: waarlijk, hij komt/ waarlijk, hij komt om de aarde te richten.

Hij zal de wereld richten in gerechtigheid/

en de volken in zijn betrouwbaarheid.

Wat het eerste opvalt, is het enjambement van "voor het aangezicht van JHWH". De aandacht die het zinsdeel stilistisch aldus krijgt, onderstreept dat het aan vers 6 en vers 9 is ontleend. De plaats "voor het aangezicht van JHWH" blijkt zich te verbreden tot de ruimte van de kosmos zelf. Was dit eerst de plaats waar Israël op bevoorrechte wijze zijn God kon ontmoeten en vervolgens de plaats waarheen Israël de volken uitnodigde, in de toekomst zal zelfs het bij uitstek onvruchtbare deel van de wereld, "de wildernis", de aanwezigheid van JHWH ervaren. Kortom, de ruimte waarin men tegenover God kan staan, zal zo wijd zijn als de kosmos zelf. 
Deze verbreding van JHWH's presentie is gebonden aan een tijdstip: "eens" (vs 12b). Dit wordt ten eerste uitgewerkt in "waarlijk, hij komt" (tweemaal in vs 13). Deze aankondiging heeft twee verbindingslijnen met het voorafgaande. De uitnodiging aan de volken om te "komen naar de voorhoven van JHWH" (vs 8) blijkt nu slechts een voorspel geweest te zijn op de allesomvattende komst van JHWH naar de aarde. Bij deze laatste van alle bewegingen is Gods tegenwoordigheid niet langer aan één plek gebonden, maar staat hij oog in oog zelfs met het ondeugdelijke gewas van de wildernis. Vervolgens staat de zin "waarlijk, hij komt" op éen lijn met "JHWH - hij maakt de hemelen" (vs Sb) en "JHWH - hij heerst als koning" (vs 10a), en wel zodanig dat "waarlijk, hij komt" het hoogtepunt vormt. Deze zin komt met vers $5 b$ en vers 10a overeen in de vorm van het werkwoord, een perfectum (de drie enige van de psalm), maar onderscheidt zich van die uitspraken over JHWH hierin dat dit de enige echt verbale zin van de psalm op het narratieve niveau vormt ${ }^{16}$. Aldus leggen de uitspraken betreffende JHWH's scheppingsmacht en zijn koningschap, in het heden ervaren, de grondslag voor de verwachting van zijn komst.

Deze derde activiteit van JHWH heeft haar eigen uitwerking: "hij komt om de aarde te richten" (vs 13b). Indien wij onze achterdocht tegen de oorspronkelijkheid van vers $10 \mathrm{c}$ handhaven, komt het thema van het wereldoordeel in vers $13 \mathrm{~b}$ voor het eerst in de psalm ter sprake. De stabiliteit van de kosmische orde hangt volgens het oudoosterse wereldbeeld ten nauwste samen met de sociale orde, de mondiale gerechtigheid. "De aarde richten" hoeft dan ook niet te betekenen "de aarde veroordelen" en zeker niet "de Israël vijandig gezinde machten te vonnissen". Het gaat om de karakteristieke plicht en het voorrecht van de heerser om de samenleving, in dit geval van de volken, met het oog op haar welzijn volgens billijkheid te leiden, waarbij het forensische aspect nauwelijks een rol speelt ${ }^{17}$. Het woord "aarde" geeft daarbij de onverbrekelijke eenheid van de kosmische en de sociale orde weer.

In vers 14 wordt het doel van Gods komst, "om de aarde te richten", uitgewerkt: "Hij zal de wereld richten in gerechtigheid en de volken in zijn betrouwbaarheid". De herhaling van de stam "richten" en de werkwoordsvorm, een imperfectum, maken de zin ondergeschikt aan vers $13 \mathrm{~b}$. Het woord "wereld" (לב verlegt de aandacht weer van het kosmische naar het sociale aspect (bewoonde wereld). Ook het parallelle woord "volken" en de bepaling "in gerechtigheid / in zijn betrouwbaarheid" versterken de ombuiging van perspectief. Evenals bij vers $13 \mathrm{~b}$ rijst nu de vraag of "wereld / volken" als aan Israël tegenovergesteld moet worden begrepen. Brengt JHWH bij zijn komst de iustitia retributiva, die Israël in zijn omgang met de volken zo vaak pijnlijk heeft gemist?

Ik ben van mening dat dit niet het geval is. Mocht de term "volken" in vers 3 nog die connotatie bezitten, de eigen dynamiek van de psalm, vooral Israëls uitnodiging aan de volken (vs 7-9), heeft alle bijklank van rivaliteit uitgewist. Trouwens, ook de verwoording van vers 14 zelf wijst in die richting, met name het allerlaatste woord van de psalm: "in zijn betrouwbaarheid". Mag het parallelle "in gerechtigheid" een vrij evidente uitwerking van het begrip "richten" behelzen, gezien het feit dat de stammen $D S U$ en $P 7 Y$ in het Oude Testament zo vaak naast elkaar voorkomen, met de bepaling "in zijn betrouwbaarheid" (let op het bezittelijk voornaamwoord!) wordt de volken de deur geopend naar een ervaring van JHWH die typisch Israël toekomt. "Betrouwbaarheid" staat voor de eigenschap dat een persoon zich steeds jegens anderen gedraagt overeenkomstig zijn diepste wezen, 
zonder daarin ooit teleur te stellen (Deut 32,4; Jes 11:5; 25:1; Hos 2:22; Ps 33:4; $36: 6 ; 40: 11 ; 88: 12 ; 89: 2,3,6,9,25,34,50 ; 92: 3 ; 98: 3 ; 100: 5 ; 143: 1$; Klaagl $3: 23)^{18}$. Als JHWH eenmaal verschijnt, zal zijn richting van de wereld beantwoorden aan wat hij voor Israël altijd heeft willen zijn. "Zijn betrouwbaarheid" connoteert genegenheid en inzet voor zijn volk in bevrijdend handelen (zie de boven vermelde teksten). Kortom, met de eigenschappen waaronder Israël hem heeft leren kennen, zal hij ook als rechter van de wereld de volken tegemoet treden. Indien en voor zover de etymologie van "betrouwbaarheid", te weten de stam "vast zijn" (IDX), nog doorklinkt in de semantische inhoud van het begrip ${ }^{19}$, ligt hier een isotopisch verband met vers $10 \mathrm{~b}$ ("De wereld zal vaststaan, zij zal niet wankelen"). De bekommernis van de volken om de stabiliteit van de wereld vindt uiteindelijk een waarborg in de betrouwbaarheid van JHWH, Israëls God, die werkelijk zal komen.

\section{Besluit}

Wij kunnen de ontwikkeling van de psalm aldus samenvaten. Israëls ervaring dat zijn God de goden van alle volken in zorg en macht te boven gaat, brengt hem er eerst toe voor deze volken een plaats naast zich in te ruimen "voor het aangezicht" van die zelfde God, dat wil zeggen bij het lofbetoon van zijn naam. Maar deze gastvrijheid beweegt Israël vervolgens tot profetische verkondiging aan die zelfde volken. De belijdenis van JHWH's koningschap houdt niet alleen een garantie voor de eigen gemeenschap in, maar biedt ook zekerheid aan de bewoners van de wereld bij hun eeuwige bekommernis om het voortbestaan van de kosmische orde. Aldus komt Israël, zij aan zij met de volken, ertoe zijn verwachting van JHWH's komst als een gunstig perspectief met hen te delen. Gods komst zal zich niet uitwerken als een bevoorrechting van Israël, maar als openbaring van wat zijn betrouwbaarheid betekent. Kortom, als degene die hij voor Israël heeft willen zijn en is geweest, zal JHWH aan de volken verschijnen 20 .

Met dit artikel betuig ik mijn grote erkentelijkheid jegens de academische staf, het administratieve personeel en de studenten van de Theologische Faculteit van de Nederduitse Gereformeerde Kerk aan de Universiteit van Pretoria voor de gastvrijheid die ik tijdens mijn verblijf aldaar (van 26 Augustus tot 5 Oktober 1991) heb genoten en voor de inspiratie die ik er heb opgedaan.

\section{NOTAS}

1 Men vindt een andere metrische indeling bij $\mathrm{H}$ Gunkel, Die Psalmen, Göttingen 51968, 420v, H-J Kraus, Psalmen (BKAT XV/2). Neukirchen ${ }^{5} 1978$, 834.

2 Gunkel, a w, 423; E Beaucamp, Le Psautier Ps 73-150 (Sources Bibliques), Paris 1979, 122; J van der Ploeg, Psalmen II (BOT VIIB), Roermond 1974, 151; J Jeremias, Das Königtum Gottes in den Psalmen. Israels Begegnung mit dem kaanäischen Mythos in den Jahwe-König-Psalmen (FRLANT 141), Göttingen 1987, 122v.

3 De vertaling "geeft, brengt" voldoen in deze context niet, want God ontleent 
zijn heerlijkheid niet aan de toegesprokenen. De vertaling "kent toe, erkent" suggereert een eenzijdige handeling van het verstand. De hier gekozen vertaling, "huldigen om", is duidelijk dynamisch-aequivalent.

4 A Baumann, לת, in: TWAT II, Stuttgart 1976, 898-902.

5 Dat deze werkwoorden als iussivi gelden, blijkt uit de vorm $ל \not D$, vergelyk J Bachmann, Präparation und Kommentar zu den Psalmen, Berlin 1891, 362v.

6 O Keel, Die Welt der altorientalischen Bildsymbolik und das Alte Testament am Beispiel der Psalmen, Zürich - Naukirchen 1972, 29-39; Kraus, a w, 837.

7 C Houtman, "De jubelzang van de struiken der wildernis in Psalm 96:12b", in Loven en Geloven (Opstellen aangeboden aan Nic H Ridderbos,), Amsterdam 1975, 151-174, vooral 169: "Onder ya'ar in Ps.96:12b valt een woestenij met jungle-achtige vegelatie te verstaan, waaraan voor de Israëliet noties verbonden waren, die in het Nederlands bijvoorbeeld een woord als rimboe oproept"; "De Israëliet heeft ernaar verlangd, dat de dreiging van de natuur, hetzij door uitroeiing, hetzij door transformatie weggenomen wordt. Zijn ideaal was niet een wereld, waarin de mens opkomt voor de rechten van wildernis en wild, maar een aarde, die rijke vruchten schenkt aan de mens (Jer.31:12; Ez.47:12 e.a.) en die daartoe geheel in cultuurland is veranderd". Vergelijk M J Mulder, רY?, in: TWAT III, Stuttgart 1981, 783-787, waar ook de ontoegangelijkheid en onherbergzaamheid van $7 \Psi$ ? wordt beklemtoond.

8 Met de tijdsbepaling I ("eens", "dan") vindt de overgang van iussivus naar indicativus plaats; vgl M Dahood, Psalms II (AB 17), Garden City, N Y 1968, 358; Jeremias, $a w, 122$.

9 Het is vooral het woordenboek van L Alonso Schökel, Diccionario Biblico Hebreo-Espanol, Valencia 1990, 30, dat bij de futurumbetekenis van toen onderscheid maakt tussen bepaald ("dan") en onbepaald ("eens"). Vergelijk ook M J Mulder, "Die Partikel äz im biblischen Hebräisch", in Studies in Hebrew and Aramaic Syntax (Presented to J Hoftijzer), edited by K Jongeling, H L Murre-Van den Berg and L van Rompay, Leiden 1991, 140.

10 R North, vרn, in: TWAT II, Stuttgart 1976, 774v.

11 J Conrad, פלא, in: TWAT VI, Stuttgart 1987, 576-583.

12 De semantische inhoud van al deze begrippen kummen wij hier niet nader omschrijven. Men zij verwezen naar de woordenboeken en theologische dictionaria.

13 I Koehler, W Baumgartner, J J Stamm, Z Ben-Hayyim, B Hartmann \& Ph H Reymond, Hebräisches und Aramäisches Lexikon zum Alten Testament IV, Leiden ${ }^{31990,} 1551$.

14 De imperfecta 1 1 drukken dit verband tussen JHWH's koningschap en de stabiliteit van de kosmos goed uit. 
15 Voor de forensische betekenis van Dיקי מי , zie L Alonso Schökel, W?, in: TWAT III, Stuttgart 1982, 1064. De context biedt geen aanleiding te vermoeden dat in deze term de rivaliteit tussen Israël en de volken een rol speelt.

16 Wij nemen daarbij in aanmerking dat vers $10 \mathrm{c}$, ook een verbale zin op het narratieve niveau, waarschijnlijk een toevoeging vormt en in ieder geval ondergeschikt is aan vers 10a: "JHWH - hij heerst als koning".

17 Vergelijk H Niehr, Herrschen und Richten. Die Wurzel DפU im Alten Orient und im Alten Testament (FzB 54). Würzburg 1986, 116v, 126.

18 A Jepsen, ID\$, in: TWAT I, Stuttgart 1973, 343w.

19 Vergelijk de discussie hierover bij J Barr, The Semantics of Biblical Language, Oxford 1961, 162-166.

20 Jeremias, ( $a w, 121-131)$, komt langs literair-historische weg tot de zelfde bevinding van die strekking van de psalm als ik (zie vooral $a w 131$ ). Maar anders dan hij $(a w, 130)$ zie ik niet de nondzaak in het perfectum $\mathrm{X}$ als een voltooid tegenwoordige tijd ("denn er ist gekommen") te vertalen. Juist de ontwikkeling binnen vers 12 en de daar ingevoerde tijdsbepaling noopt mijns inziens tot de interpretatie van $\mathrm{X} 7$ als perfectum propheticum. 